\title{
Palinotaxonomia de Albertinia brasiliensis Spreng., Eremanthus bicolor (DC.) Baker e Vanillosmopsis erythropappa (DC.) Sch. Bip. (Compositae -Vernonieae) $^{1}$
}

\author{
Aliny Férras Peçanha ${ }^{3,4}$, Roberto Lourenço Esteves² e Vania Gonçalves-Esteves ${ }^{3}$
}

Recebido em 30/01/2007. Aceito em 11/06/2007

\begin{abstract}
RESUMO - (Palinotaxonomia de Albertinia brasiliensis Spreng., Eremanthus bicolor (DC.) Baker e Vanillosmopsis erythropappa (DC.) Sch. Bip. (Compositae-Vernonieae)). Vanillosmopsis Sch. Bip. tem sido, tradicionalmente, aceito como sinônimo de Eremanthus Less. e o gênero Albertinia Spreng. foi estabelecido para abrigar Albertinia brasiliensis Spreng. O presente trabalho propõe a caracterização polínica de Albertinia brasiliensis, Vanillosmopsis erythropappa e Eremanthus bicolor e fornece subsídios para futuros estudos taxonômicos. Foram utilizados grãos de pólen de espécimens coletados em diferentes herbários. As duas primeiras espécies são encontradas no Rio de Janeiro enquanto Eremanthus Less. não. Assim, optou-se por utilizar a espécie-tipo do gênero na análise polínica. Os grãos de pólen foram acetolisados, medidos, descritos e ilustrados usando microscopia de luz. Grãos de pólen não acetolisados foram usados para análise em microscopia eletrônica de varredura. O resultado do estudo polínico mostrou que as espécies podem ser separadas utilizando-se, principalmente, as características das aberturas e da ornamentação da exina e revelou uma gradação evolutiva interespecífica dos caracteres polínicos. Com relação à taxonomia das espécies estudadas, os dados palinológicos comprovam a posição taxonômica de Albertinia brasiliensis, porém não reforça a sinonimização de Vanillosmopsis em Eremanthus.
\end{abstract}

Palavras-chave: palinotaxonomia, gradação interespecífica, Compositae

ABSTRACT - (Palynotaxonomy of Albertinia brasiliensis Spreng., Eremanthus bicolor (DC.) Baker and Vanillosmopsis erythropappa (DC.) Sch. Bip. (Compositae-Vernonieae)). Vanillosmopsis Sch. Bip. has been traditionally accepted as a synonym of Eremanthus Less., and Albertinia Spreng. was established to include Albertinia brasiliensis Spreng. This paper characterizes the pollen of Albertinia brasiliensis, Vanillosmopsis erythropappa and Eremanthus bicolor and provides information for future taxonomic studies. Pollen grains of specimens collected in different herbaria were used in this study. The two first species are found in Rio de Janeiro, but Eremanthus is not found in this state. For this reason, the type species of this genus was used for pollen analysis. Pollen grains were acetolysed, measured, described and illustrated using optical microscopy. Non-acetolysed pollen grains were used for analysis in scanning electron microscopy. The results showed that these species can be distinguished using mainly exine ornamentation and aperture features, revealing an interspecific evolutionary gradation of pollen characteristics. As regards the taxonomy of the species studied, the palynological data confirm the taxonomic position of Albertinia brasiliensis, but they do not support the subordination of Vanillosmopsis to Eremanthus.

Key words: palynotaxonomy, interspecific gradation, Compositae

\section{Introdução}

Albertinia brasiliensis foi descrita por Sprengel (1826) como uma espécie arbustiva, que se separa das espécies afins por duas características ligadas à estrutura do capítulo: invólucro com brácteas muito mais curtas do que as flores e receptáculo dotado de alvéolos profundos que envolvem completamente os aquênios.
Lessing (1831 apud Bremer 1994), numa avaliação superficial do capítulo de Albertinia brasiliensis Spreng., interpretou erroneamente cada alvéolo profundamente escavado como um capítulo individual, presumindo, assim, que a estrutura representava uma inflorescência secundária formada por dezenas de capítulos estreitamente aglomerados, num exemplo de sincefalia. Essa interpretação errônea foi seguida por De Candolle (1836) que ampliou a circunscrição

\footnotetext{
Parte da Dissertação de Mestrado da primeira Autora

2 Universidade do Estado do Rio de Janeiro, Instituto de Biologia, DBAV, Rua São Francisco Xavier 254, Maracanã, 20550-013 Rio de Janeiro, RJ, Brasil (esteves@uerj.br)

3 Museu Nacional, Universidade Federal do Rio de Janeiro, Departamento de Botânica, Quinta da Boa Vista, São Cristóvão, 20940-040 Rio de Janeiro, RJ, Brasil (vesteves@ acd.ufrj.br)

4 Autor para correspondência: acerdeira@netterra.com.br
} 
genérica de Albertinia agregando, sob este gênero, diversas outras espécies com capítulos sincéfalos como Eremanthus Less. e Vanillosmopsis Sch.-Bip. Coube a Schultz-Bipontinus (1861) a interpretação morfológica correta do capítulo de Albertinia mantendo neste gênero apenas a espécie Albertinia brasiliensis criada por Sprengel (1826). As demais espécies de Albertinia foram transferidas por Schultz-Bipontinus (1861) para Eremanthus ou para Vanillosmopsis.

Eremanthus foi estabelecido por Lessing (1829 apud MacLeish 1987) para incluir as espécies arborescentes ou arbustivas com capítulos unifloros intimamente agregados em inflorescências congestas (sincefalia), com a série mais interna do papus com os elementos achatados (paleáceo), espiralados e decíduos. Já as espécies com muitas flores por capítulo e papus filiforme, ou foram abrigadas por este autor em Vernonia Schreb. (se herbáceas) ou em Albertinia (se arbustos ou arvoretas).

Vanillosmopsis foi fundado por Schultz-Bipontinus (1861) para abrigar as demais espécies retiradas por este autor do gênero Albertinia e que possuem em comum o conjunto dos seguintes atributos: uma a três (raramente quatro) flores por capítulo, grau de fusão dos capítulos (sincefalia) variável e aquênio com papus caduco, com cerdas filiformes.

Baker (1873), aceitou os gêneros Albertinia, Vanillosmopsis e Eremanthus, o primeiro como monotípico, com Albertinia brasiliensis. Com base no grau de sincefalia dos capítulos, caducidade ou persistência do papus e a forma dos seus elementos, Baker (1873) combinou sob Eremanthus ou sob Vanillosmopsis todas as espécies até então descritas sob Albertinia. As fronteiras estabelecidas por Baker (1873) para os três gêneros supracitados e para os demais gêneros da tribo Vernonieae permaneceram quase inalteradas por cerca de cem anos. Esta visão taxonômica começou a ser gradualmente alterada a partir de 1987 pelos trabalhos de Robinson (1987a; b; c) ao estabelecer Echinocoryne Robinson (1987a), Cyrtocymura (Robinson 1987b) e ao restabelecer Stenocephalum (Robinson 1987c) gênero criado originalmente por Schultz-Bipontinus (1863) e tratado por Baker (1873) sob Vernonia. Esses trabalhos foram seguidos por muitos outros como Robinson (1988a; b; $1989 ; 1992 \mathrm{a}$; b) que modificaram substancialmente os limites genéricos, principalmente de Vernonia Schreb. A atual posição taxonômica dos gêneros de Vernonieae tratados por Robinson e por sucessivos autores foi sumariada por Robinson (1999).
MacLeish (1987) revisou o gênero Eremanthus sob um conjunto mais abrangente de caracteres, tais como: hábito, indumento, presença ou não de tricomas estrelados, grau de sincefalia dos capítulos, número de flores por capítulo, tamanho relativo das brácteas involucrais, presença ou não de alvéolos no receptáculo, características do papus (se caduco ou persistente, com elementos paleáceos ou filiformes) e número de costas ou ângulos dos aquênios (10, raramente 20 costas). MacLeish (1987) não utilizou nesse estudo recursos filogenéticos, dados polínicos ou anatômicos. Em seus resultados seguiu a posição estabelecida por SchultzBipontinus (1861) e consagrada por Baker (1873), interpretando Albertinia como monotípico. Entretanto, desconsiderou Vanillosmopsis como um gênero autônomo e combinou suas espécies sob Eremanthus.

Na bibliografia palinológica, apenas Stix (1960), durante a caracterização do padrão de ornamentação da exina para a tribo Vernonieae, citou a condição equinada como típica para esta tribo, sendo encontrada nas espécies de Vernonia e Albertinia. Com relação ao gênero Eremanthus, já existem descrições sobre a sua morfologia polínica realizada por Gleason (1922) que o denominou de "tipo A incomum", ou seja, com um padrão intermediário entre o subequinolofado e o lofado e o classificou na categoria de "sublofado", terminologia que também está sendo adotada no presente trabalho.

Muitos autores criaram tipos polínicos, como por exemplo, Kingham (1976) que através do estudo da morfologia polínica de 85 espécies africanas da tribo Vernonieae, reconheceu seis tipos de grãos de pólen (I-VI) com base nas seguintes características: ornamentação da exina, tipo de abertura e ausência ou presença de microperfurações. Estes tipos foram diferenciados por apresentarem grãos de pólen lofados, triporados, com microperfurações ausentes (Tipo I); equinolofados, triporados, com microperfurações presentes (Tipo II); lofados, tricolporados, com microperfurações ausentes (Tipo III); equinolofados, tricolporados, com microperfurações presentes (Tipo IV); equinolofados a subequinolofados, tricolporados, com microperfurações presentes (Tipo V) e subequinolofados a equinados, tricolporados, com microperfurações presentes (Tipo VI).

Keeley \& Jones (1977) reconheceram nas Compositae quatro "tipos polínicos" (A, B, C e B-C) com base na ornamentação, comprimento dos espinhos, microperfurações no teto e aberturas. O "tipo A" é caracterizado como apresentando grãos de pólen 
equinados a subequinolofados, tricolporados, teto microperfurado, espinhos sobre cristas nos grãos de pólen subequinolofados; o "tipo B" é definido por possuir grãos de pólen equinolofados, tricolporados, teto com microperfurações descontínuas, espinhos, geralmente, pronunciados nos muros, sendo ocasionalmente reduzidos e muros polares coincidentes; $\mathrm{O}$ "tipo C" é definido por ter grãos de pólen equinolofados, tricolporados, teto com microperfuração descontínua, alguns espinhos reduzidos no muro e lacuna polar proeminente e o "tipo B-C" com um muro polar que coincide com a lacuna polar.

Robinson (1999) utilizando características polínicas, dentre outras, em sua nova organização genérica, considerou Albertinia, Eremanthus e Vanillosmopsis como possuindo grãos de pólen do tipo A.

O presente estudo propõe a caracterização palinológica de Eremanthus bicolor, Albertinia brasiliensis e Vanillosmopsis erythropappa e fornecer subsídios para futuros estudos taxonômicos na tribo Vernonieae.

\section{Material e métodos}

O material polínico analisado foi retirado de exsicatas depositadas nos seguintes herbários nacionais: GUA, RB, R, UEC. As siglas dos herbários estão de acordo com Holmgren et al. (1990).

Para cada espécie determinou-se um espécimen como "padrão", indicado por asterisco junto à sigla do herbário depositário, realizando-se um estudo pormenorizado de seus grãos de pólen. Os dos outros espécimes de cada espécie, denominados "materiais de comparação" foram examinados com a finalidade de se estabelecer comparações através da relação entre as medidas dos diâmetros polar e equatorial. Segue a relação do material estudado: Albertinia brasiliensis Spreng. - BRASIL. Rio de Janeiro: Baixada Fluminense, 8/IV/1959, A.P. Duarte 4690 \& E. Pereira s.n. (RB); Alto do Corcovado, 12/XII/1868, Glaziou 552 (R); Campo Grande, Serra do Mendanha, 4/IV/1978, H.C. de Lima 324 et al. (*RB); Base da Pedra da Panela, 3/XI/1971, D. Sucre 7864 (R); Corcovado, XII/1894, E. Ule 4269 (R). Eremanthus bicolor (DC.) Baker - BRASIL. Minas Gerais: Diamantina, a caminho de Conselheiro da Mata, 18/V/1990, M.M. Arbo et al. 4353 (UEC); Diamantina, estrada para Conselheiro da Mata, 18/VII/1980, N.L. Menezes et al. s.n. (*UEC24533); Diamantina, 18/VII/1980, N.L. Menezes et al. s.n.
(UEC35001). Vanillosmopsis erythropappa (DC.) Sch. Bip. - BRASIL. Rio de Janeiro: Floresta da Tijuca, 30/XI/1927, Antenor 180 (RB); Floresta da Tijuca, estrada das Paineiras, 31/VIII/1985, C. Farney $793 b$ \& D.M. Pena (*RB); Pico da Tijuca, 21/VI/1929, Brade 10441 (R); Vista Chinesa, 2/VII/1939, Brade 16122 (RB); Tijuca, estrada da Vista Chinesa-Gávea Pequena, 12/VII/1969, J.P. Lanna 1811 (GUA).

Do material herborizado foram retirados flores ou botões florais que foram fixados em ácido acético glacial precedendo a aplicação do método de acetólise de Erdtman (1952) para que previamente ocorra a desidratação dos grãos de pólen facilitando a ação da mistura de acetólise. Os grãos de pólen acetolisados foram montados em gelatina glicerinada e distribuídos em um mínimo de três lâminas. Estas foram cobertas com lamínulas e o conjunto foi vedado com parafina. Foram utilizados pequenos pedaços de massa de modelar nos ângulos da lamínula, com a finalidade de evitar o amassamento dos grãos de pólen causado pela pressão da lamínula Melhem \& Matos (1972).

As mensurações foram realizadas num prazo máximo de sete dias, a fim de evitar alterações nas dimensões dos grãos de pólen segundo SalgadoLabouriau (1973). Do material padrão foram medidos o diâmetro polar (DP) e o equatorial (DE) nos grãos de pólen em vista equatorial. As medidas foram realizadas, aleatoriamente, em cerca de 25 grãos de pólen, distribuídos num mínimo em três lâminas e, em seguida, calculou-se a média aritmética ( ), o desvio padrão da amostra (s), o desvio padrão da média (s ), o coeficiente de variabilidade (CV\%) e o intervalo de confiança a 95\%. Em grãos de pólen em vista polar foram realizadas 10 medidas das camadas da exina (sexina e nexina), do lado do apocolpo (LA) e do diâmetro equatorial (DEVP). Em vista equatorial, foram tomadas as medidas do diâmetro das aberturas. Dos espécimes de comparação foram medidos o DP e o DE determinando-se o tamanho e, da relação entre os dois diâmetros (DP/DE) chegou-se à forma segundo Erdtman (1952).

Para classificar os espinhos em longos e curtos, largos e estreitos, foi estabelecido, com base nos resultados da Tab. 4 , as seguintes classes de tamanho: $\geq 5,1 \mu \mathrm{m}$ - longos; $\leq 5,0 \mu \mathrm{m}$ - curtos; $\geq 2,3 \mu \mathrm{m}$ - largos; $\leq 2,3 \mu \mathrm{m}$ - estreitos. Para classificar a largura dos colpos, com base nos resultados da Tab. 4, foram estabelecidas as seguintes classes de tamanho: $\leq 5,1 \mu \mathrm{m}$ - estreitos; 5,2-8,9 $\mu \mathrm{m}$ - largos; $\geq 9,0 \mu \mathrm{m}$ muito largos. 
316 Peçanha, Esteves \& Gonçalves-Esteves: Palinotaxonomia de Albertinia brasiliensis Spreng., Eremanthus bicolor...

As fotomicrografias foram realizadas com equipamento Hund H-500, objetivas de 100X. Para análise em microscópio eletrônico de varredura, as anteras foram maceradas e os grãos de pólen pulverizados sobre suportes recobertos por fita dupla-face de carbono. O conjunto foi metalizado com uma fina camada de ouro paládio por cerca de três minutos sendo, posteriormente, analisado em aparelho Zeiss DSM960.

Utilizou-se a sequiência padronizada por Erdtman (1969) para as descrições polínicas. A terminologia empregada para a caracterização dos grãos de pólen está de acordo com Punt et al. (1999).

\section{Resultados}

\section{Albertinia brasiliensis Spreng.}

Fig. 1-7

Grãos de pólen médios, isopolares, oblatoesferoidais, âmbito subtriangular, área polar pequena, tricolporados, exina subequinolofada (Tab. 1-4).

Abertura: três cólporos, colpos longos, largos (Tab. 4) recobertos por membrana ornamentada, endoabertura circular, sem constricção mediana. Observa-se uma fileira formada por sete a oito pares de espinhos margeando a abertura.

Exina: subequinolofada (Fig. 2, 3, 7), simplescolumelada, formada por muros sinuosos encimados por espinhos longos, estreitos (Tab. 4). Os muros se tornam largos na base dos espinhos apresentando muitas perfurações, tanto próximas aos espinhos, quanto nas depressões entre os muros (Fig. 7). Em vista polar, na região do apocolpo (Fig. 2, 3), o muro não tem um padrão definido de ornamentação. Em vista equatorial, próximo à abertura, alguns grãos de pólen apresentam uma "malha" formada pela união das bases alargadas dos muros (Fig. 5, 6). Em microscopia eletrônica de varredura (MEV) pode-se observar que as regiões de depressão entre os muros são estreitas, profundas e possuem pequenas perfurações (Fig. 7). A sexina é mais espessa do que a nexina (Tab. 4).

A maioria dos espécimens analisados, para comparação, apresentou grãos de pólen com valores dos diâmetros polar e equatorial fora dos limites do IC a $95 \%$ porém, dentro dos limites da faixa de variação quando comparados com o material padrão (Tab. 5).

\section{Eremanthus bicolor (DC.) Baker}

Fig. 14-20

Grãos de pólen médios a grandes, isopolares, oblato-esferoidais, âmbito subcircular, área polar pequena, tricolporados, exina com padrão sublofado, intermediário entre o padrão subequinolofado e o padrão lofado (Tab. 1-4).

Abertura: três cólporos, colpos longos, estreitos, endoabertura lalongada (Tab. 4). Os colpos possuem membrana ornamentada. A endoabertura apresenta, às vezes, constricção mediana e é acentuadamente lalongada, ultrapassando os limites do colpo (Fig. 16, 17). Observam-se três pares de lacunas margeando a abertura (Fig. 17, 20).

Exina: simplescolumelada, com padrão sublofado de ornamentação, isto é, intermediário entre o lofado

Tabela 1. Caracterização morfológica dos grãos de pólen de espécies de Vernonieae. DP - diâmetro polar; DE - diâmetro equatorial.

\begin{tabular}{lcccc}
\hline Espécies & Tamanho & Âmbito & Ornamentação da exina & DP/DE \\
\hline Albertinia brasiliensis Spreng. & médio & subtriangular & subequinolofada & 0,92 \\
$\begin{array}{l}\text { Eremanthus bicolor } \text { Less. } \\
\text { Vanillosmopsis erythropappa } \text { (DC.) Sch. Bip. }\end{array}$ & $\begin{array}{c}\text { médio a grande } \\
\text { médio a grande }\end{array}$ & $\begin{array}{c}\text { sublofada } \\
\text { subequinolofada }\end{array}$ & 0,90 \\
\hline
\end{tabular}

Tabela 2. Medidas $(\mathrm{em} \mu \mathrm{m})$ dos grãos de pólen, em vista equatorial, de espécies de Vernonieae $(\mathrm{n}=25)$. ( - média aritmética; $\mathrm{s}$ - desvio padrão da média; IC - intervalo de confiança).

\begin{tabular}{|c|c|c|c|c|c|c|}
\hline \multirow[t]{2}{*}{ Espécies } & \multicolumn{3}{|c|}{ Diâmetro polar } & \multicolumn{3}{|c|}{ Diâmetro equatorial } \\
\hline & Faixa de variação & $\pm \mathrm{s}$ & IC $95 \%$ & Faixa de variação & $\pm s$ & IC95\% \\
\hline Albertinia brasiliensis Spreng. & $40,0-50,0$ & $43,4 \pm 0,3$ & $42,8-44,0$ & $42,5-50,0$ & $47,0 \pm 0,4$ & $46,2-47,8$ \\
\hline Eremanthus bicolor Less. & $45,0-52,5$ & $48,2 \pm 0,4$ & $47,4-49,1$ & $50,0-55,0$ & $53,5 \pm 0,3$ & $52,9-54,1$ \\
\hline $\begin{array}{l}\text { Vanillosmopsis erythropappa } \\
\text { (DC.) Sch. Bip. }\end{array}$ & $45,0-50,0$ & $46,6 \pm 0,3$ & $46,0-47,2$ & $45,8-52,5$ & $49,0 \pm 0,4$ & $48,3-49,9$ \\
\hline
\end{tabular}


Tabela 3. Medidas (em $\mu$ m) dos grãos de pólen, em vista polar, de espécies de Vernonieae - diâmetro equatorial, lado do apocolpo (LA) e índice da área polar (IAP) $(\mathrm{n}=10)$.

\begin{tabular}{lllll}
\hline Espécies & \multicolumn{2}{c}{ Diâmetro equatorial } & \multirow{2}{*}{ LA } & IAP \\
\cline { 2 - 5 } \multicolumn{2}{c}{ Faixa de variação } & & \\
\hline $\begin{array}{l}\text { Albertinia brasiliensis } \text { Spreng. } \\
\text { Eremanthus bicolor Less. }\end{array}$ & $42,5-50,0$ & 46,0 & 13,0 & 0,28 \\
$\begin{array}{l}\text { Vanillosmopsis erythropappa } \\
\text { (DC.) Sch. Bip. }\end{array}$ & $42,5-50,0$ & 48,4 & 14,0 & 0,29 \\
& & & & \\
\hline
\end{tabular}

típico e o subequinolofado (Fig. 17, 18, 19, 20). Os muros que formam as lacunas são pouco sinuosos encimados por espinhos curtos e estreitos (Tab. 4) e apresentam muitas perfurações (Fig. 19). As regiões de depressão entre os muros possuem perfurações e ondulações. Observando a vista lateral na região do mesocolpo, constata-se a presença de lacunas (Fig. 19, 20), porém em vista polar, o apocolpo é constituído por muros sem formar lacunas (Fig. 15), mas, organizados em pequenos trechos de muros isolados. Os espinhos estão localizados nas elevações dos muros e apresentam perfurações próximas à sua base.

Os espécimes de comparação analisados apresentaram grãos de pólen com valores dos diâmetros polar e equatorial dentro dos limites da faixa de variação e, apenas, os diâmetros equatoriais permanecem nos limites do IC 95\% quando comparados com o material padrão.
Vanillosmopsis erythropappa (DC.) Sch. Bip.

Fig. 8-13

Grãos de pólen médios a grandes, isopolares, oblato-esferoidais, âmbito subtriangular, área polar pequena, tricolporados, exina subequinolofada (Tab. 1-4).

Abertura: três cólporos, colpos longos, muito largos, recobertos por membrana lisa; endoabertura lalongada ampla (Tab. 4), com constricção mediana (Fig. 11). Observa-se uma fileira com cinco a seis pares de espinhos margeando a abertura.

Exina: subequinolofada (Fig. 8, 9, 13), simplescolumelada; os muros que formam a exina mostram um relevo pouco sinuoso. Os espinhos são longos e largos (Tab. 4), com perfurações na base e estão localizados nas elevações dos muros (Fig. 12, 13). Em vista polar, o muro não tem um padrão definido de ornamentação. A sexina entre os muros apresenta depressões espaçadas, pouco profundas, com muitas perfurações conspícuas (Fig. 13). Em vista equatorial, os grãos de pólen apresentam grandes "malhas", pouco profundas, formadas por muros contínuos (Fig. 11, 12). A sexina é mais espessa do que a nexina (Tab. 4).

A maioria dos espécimens analisados para comparação apresentou grãos de pólen com valores dos diâmetros polar e equatorial fora dos limites do IC a $95 \%$ e da faixa de variação quando comparados com o material padrão.

Chave polínica para identificação de Albertinia brasiliensis Spreng., Eremanthus bicolor (DC.) Baker e Vanillosmopsis erythropappa (DC.) Sch. Bip.

1. Grãos de pólen com exina sublofada; em vista polar, o apocolpo é constituído por muros sem formar lacunas, organizados em pequenos trechos isolados de muros

Eremanthus bicolor

1. Grãos de pólen com exina subequinolofada; em vista polar, no apocolpo, o muro não tem um padrão definido de ornamentação

2. Endoabertura circular, sem constricção mediana.....

Albertinia brasiliensis

2. Endoabertura lalongada ampla, com constricção mediana Vanillosmopsis erythropappa

Tabela 4. Médias (em $\mu \mathrm{m})$ das medidas das aberturas e das camadas da exina dos grãos de pólen de espécies de Vernonieae $(\mathrm{n}=10)$. (compr. - comprimento; larg. - largura; DEE - distância entre os espinhos; * - espessura da sexina entre os espinhos).

\begin{tabular}{|c|c|c|c|c|c|c|c|c|c|c|c|}
\hline \multirow[t]{2}{*}{ Espécies } & \multicolumn{2}{|c|}{ Colpo } & \multicolumn{2}{|c|}{ Endoabertura } & \multicolumn{3}{|c|}{ Espinhos } & \multirow[b]{2}{*}{ total } & \multicolumn{3}{|c|}{ Exina } \\
\hline & compr. & larg. & compr. & larg. & compr. & larg. & $\overline{\mathrm{DEE}}$ & & sexina* & $\begin{array}{c}\text { sexina } \\
\text { total }\end{array}$ & nexina \\
\hline Albertinia brasiliensis Spreng. & 19,6 & 5,4 & 5,2 & 5,2 & 5,1 & 1,9 & 7,4 & 11,1 & 3,8 & 8,9 & 2,1 \\
\hline Eremanthus bicolor Less. & 22,6 & 5,1 & 4,4 & 6,6 & 3,7 & 2,0 & 7,8 & 11,0 & 5,3 & 9,0 & 2,0 \\
\hline $\begin{array}{l}\text { Vanillosmopsis erythropappa } \\
\text { (DC.) Sch. Bip. }\end{array}$ & 21,1 & 11,4 & 8,3 & 11,4 & 5,3 & 2,3 & 8,1 & 12,2 & 4,6 & 9,8 & 2,4 \\
\hline
\end{tabular}


318 Peçanha, Esteves \& Gonçalves-Esteves: Palinotaxonomia de Albertinia brasiliensis Spreng., Eremanthus bicolor...
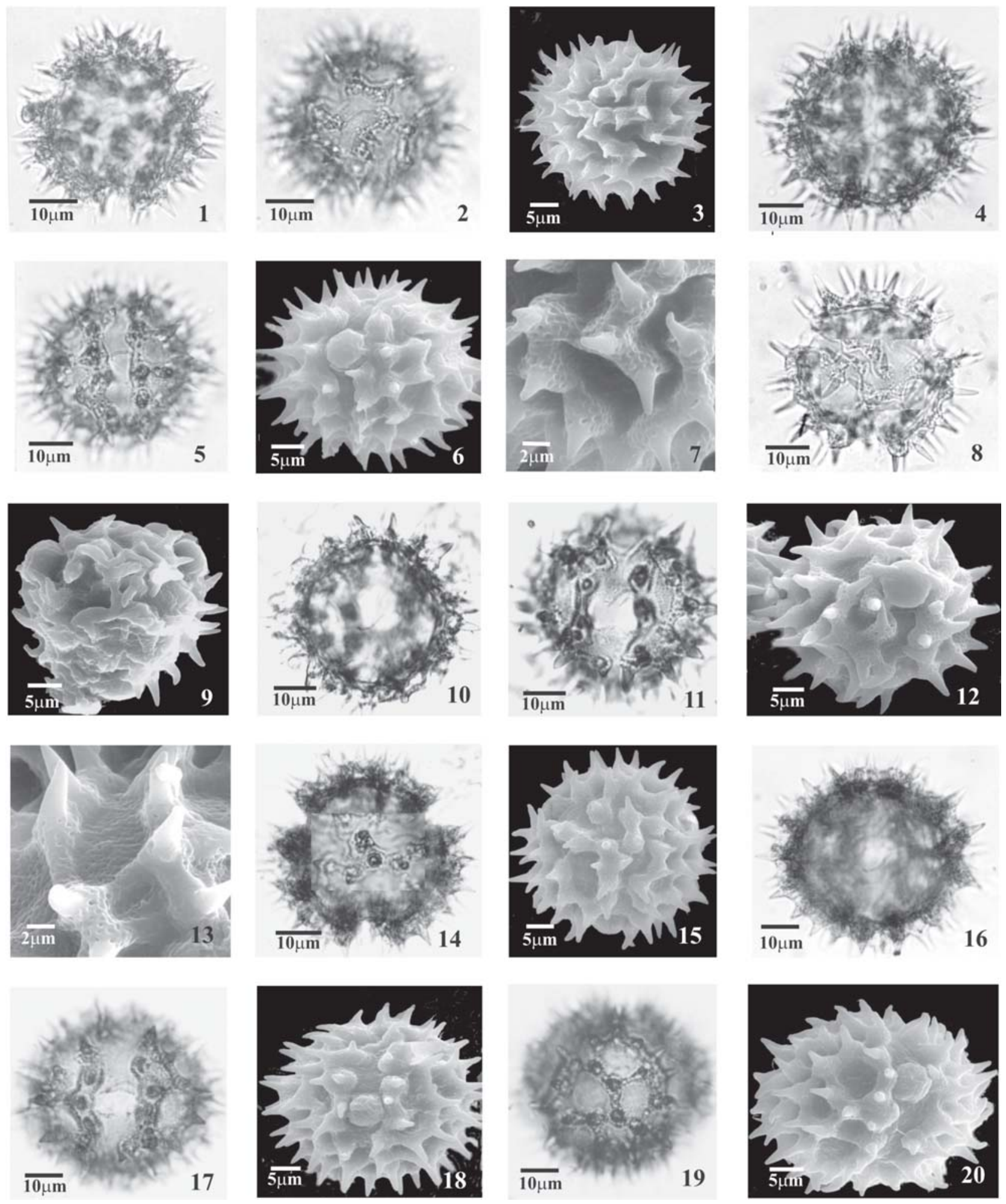

Figuras 1-7. Fotomicrografias e eletromicrografias dos grãos de pólen de espécies de Albertinia brasiliensis Spreng. - vista polar: 1. Corte óptico. 2-3. (MEV) - superfície na região do apocolpo; vista equatorial: 4. Corte óptico. 5-6. (MEV) - abertura. 7. (MEV) - detalhe da superfície. Figuras 8-13. Vanillosmopsis erythropappa (DC.) Sch. Bip.- vista polar: 8. Corte óptico. 9. (MEV) - superfície na região do apocolpo; vista equatorial: 10. Corte óptico. 11-12. (MEV) - abertura. 13. (MEV) - detalhe da superfície. Figuras 14-20. Eremanthus bicolor Less. - vista polar: 14. Corte óptico. 15. (MEV) - superfície na região do apocolpo; vista equatorial. 16. Corte óptico. 17-18. (MEV) - abertura. 19. Região do mesocolpo evidenciando as malhas. 20. (MEV) - vista lateral mostrando a abertura e as malhas no mesocolpo. 
Tabela 5. Média (em $\mu \mathrm{m}$ ) dos diâmetros polar (DP) e equatorial (DE), em vista equatorial e forma dos grãos de pólen do material de comparação de espécies de Vernonieae $(\mathrm{n}=10)$.

\begin{tabular}{|c|c|c|c|c|}
\hline Espécies & DP & $\mathrm{DE}$ & $\mathrm{P} / \mathrm{E}$ & Forma \\
\hline \multicolumn{5}{|l|}{ Albertinia brasiliensis Spreng. } \\
\hline A.P. Duarte 4690 \& E. Pereira s.n. & 45,2 & 47,0 & 0,96 & oblato-esferoidal \\
\hline Glaziou 552 & 42,8 & 47,7 & 0,90 & oblato-esferoidal \\
\hline E. Ule 4269 & 40,8 & 44,0 & 0,93 & oblato-esferoidal \\
\hline D. Sucre 7864 & 45,3 & 48,6 & 0,93 & oblato-esferoidal \\
\hline \multicolumn{5}{|l|}{ Eremanthus bicolor Less. } \\
\hline M.M. Arbo et al. 4353 & 49,4 & 53,2 & 0,93 & oblato-esferoidal \\
\hline N.L. Menezes et al. s.n. & 49,8 & 53,2 & 0,94 & oblato-esferoidal \\
\hline \multicolumn{5}{|c|}{ Vanillosmopsis erythropappa (DC.) Sch. Bip. } \\
\hline Antenor 180 & 52,0 & 55,0 & 0,94 & oblato-esferoidal \\
\hline Brade 10441 & 46,5 & 50,0 & 0,93 & oblato-esferoidal \\
\hline J.P. Lanna 1811 & 48,2 & 54,0 & 0,89 & oblato-esferoidal \\
\hline Brade 16122 & 51,2 & 55,0 & 0,93 & oblato-esferoidal \\
\hline
\end{tabular}

\section{Discussão}

O estudo da morfologia polínica das três espécies permitiu separá-las através de dois caracteres polínicos principais: a ornamentação da exina e a forma da endoabertura, embora também tivesse ocorrido variação em outros caracteres como o âmbito e o tamanho.

Com relação à ornamentação da exina, os grãos de pólen de Eremanthus bicolor revelaram um padrão intermediário entre o tipo subequinolofado e lofado (sublofado), enquanto que em Albertinia brasiliensis o padrão foi definido como subequinolofado típico, embora apresentasse, em algumas regiões da superfície, "malhas" formadas pelo alargamento das bases dos muros; em Vanillosmopsis erythropappa o padrão é, também, subequinolofado típico, porém, as "malhas" são mais largas, pouco profundas, intensamente perfuradas e formadas por muros contínuos. A endoabertura apresentou variação na forma sendo circular em A. brasiliensis e lalongada em Vanillosmopsis erythropappa e Eremanthus bicolor.

Stix (1960) citou a condição equinada para as espécies de Albertinia, o que diverge com as informações aqui obtidas para a espécie Albertinia brasiliensis, pois esta apresenta a exina com o padrão de ornamentação subequinolofado.

De acordo com os tipos polínicos criados por Keeley \& Jones (1977) as espécies Albertinia brasiliensis e Vanillosmopsis erythropappa foram aqui enquadradas no "tipo A" por apresentarem grãos de pólen subequinolofados, tricolporados, com teto microperfurado e espinhos ocorrendo sobre os muros. Com relação à espécie Eremanthus bicolor, foi confirmado, no presente estudo, o tipo sublofado ("tipo A incomum") criado por Gleason (1922).

Kingham (1976) definiu seis tipos de grãos de pólen com base no estudo polínico de 85 espécies africanas da tribo Vernonieae. Segundo este autor, o Tipo V constitui uma tendência de reversão do grão de pólen de padrão equinolofado ao subequinolofado. De acordo com o mesmo autor, a tendência evolutiva dentro dos tipos de pólen da família Compositae caminha dos tipos mais primitivos equinado/ subequinolofado para os tipos mais avançados equinolofado a psilolofado. Com base na classificação dos seis tipos de grãos de pólen definidos por Kingham (1976) apenas os grãos de pólen de Albertinia brasiliensis e Vanillosmopsis erythropappa puderam ser enquadrados no Tipo V, enquanto os grãos de pólen de Eremanthus bicolor não se aproximaram de nenhum dos tipos criados pelo autor.

Robinson (1999) estudou a morfologia polínica nas tribos Vernonieae e Lactuceae e encontrou na primeira tribo uma quantidade de casos isolados de grãos de pólen do padrão lofado revertendo, aparentemente, para o "tipo A" criado por Keeley \& Jones (1977), dentro de gêneros ou de grupos genéricos bem definidos como em Cyrtocymura H. Rob., Eirmocephala H. Rob., Lessingianthus H. Rob. e Lepidaploa Cass. Ainda neste trabalho, o referido autor discute o fato da impossibilidade do padrão lofado ter, independentemente e repetidamente, sido derivado apenas do 
"tipo A" simples, pois o padrão lofado ocorre em toda a tribo, mesmo em diferentes ambientes. De acordo com Robinson (1999), aparentemente, a reversão do grão de pólen do "tipo A" a partir da forma lofada tem se fixado em alguns grupos de Vernonieae neotropicais, tais como Lychnophorinae, Piptocarphinae e em elementos de Vernonia-Vernonanthura de Vernoniinae. Não existem evidências nas Vernonieae neotropicais do "tipo A" revertendo-se para as formas lofadas, mas a variação do pólen no gênero Distephanus Cass. do Velho Mundo envolve uma forma lofada que difere do "tipo A" somente na continuidade das diferentes partes da exina (Robinson \& Kahn 1986, apud Robinson 1999) e mudanças observadas comumente em ambas direções neste gênero.

As espécies aqui estudadas apesar de se mostrarem distintas em alguns caracteres polínicos, apresentaram uma gradação em relação ao padrão de ornamentação. Esta gradação inicia-se no subequinolofado típico, encontrado em Albertinia brasiliensis e caracterizado pela presença de "malhas" formadas pela união das bases alargadas dos muros em algumas regiões da superfície; o mesmo padrão subequinolofado típico em Vanillosmopsis erythropappa, porém apresentando alguns caracteres distintos como "malhas" mais largas, pouco profundas, intensamente perfuradas e formadas por muros contínuos ["tipo A" de Keeley \& Jones (1977) e/ou Tipo V de Kingham (1976)]; o padrão subseqüente aos demais apresentados que representa o nível final da gradação, o sublofado ou "tipo A incomum" [criado por Gleason (1922)] com lacunas evidentes somente em vista lateral na região do mesocolpo é encontrado em Eremanthus bicolor. Esta gradação poderá ou não revelar a reversão descrita por Robinson (1999) do grão de pólen do "tipo A" das formas lofadas, envolvendo a espécie Albertinia brasiliensis (subtribo Vernoniinae) e as espécies Vanillosmopsis erythropappa e Eremanthus bicolor (subtribo Lychnophorinae). A gradação de caracteres apresentada pelas três espécies também poderá ou não mostrar a tendência evolutiva (do padrão mais primitivo, observado no gênero Albertinia ao padrão mais evoluído no gênero Eremanthus) para os tipos de pólen observados na família Compositae segundo Kingham (1976). No entanto, se faz necessário que um número maior de espécimens seja analisado a fim de fortalecer a provável reversão dos tipos polínicos e a seqüência evolutiva dos caracteres polínicos destas espécies.
O presente estudo comprova a separação polínica de Albertinia brasiliensis, Eremanthus bicolor e Vanillosmopsis erythropappa. Quanto ao tratamento taxonômico dado aos três gêneros, o trabalho confirma a posição taxonômica de Macleish (1987) para espécie Albertinia brasiliensis, porém não reforça a sinonimização proposta do gênero Vanillosmopsis em Eremanthus de acordo com a autora supracitada.

\section{Agradecimentos}

Ao Laboratório de Microscopia Eletrônica da PUC-Rio na pessoa MSc. Maria de Fátima Lopes "in memoriam" que forneceu condições de trabalho para a obtenção de eletromicrografias; ao CNPq, pela bolsa concedida à última autora, à FUJB e à FAPERJ, pelos auxílios concedidos.

\section{Referências bibliográficas}

Baker, J.G. 1873. Compositae II. Eupatoriaceae. Pp. 181-374. In: C.F.P. de Martius (eds.). Flora Brasiliensis. München, Frid. Fleischer.

Bremer, K. 1994. Asteraceae, Cladistics and Classification. Portland, Oregon, Timber Press.

De Candolle, A.P. 1836. Compositae-Eupatoriaceae, part I. Pp. 103-211. In: A.P. De Candolle (ed.). Prodromus Systematis Regni Vegetabilis. Paris. Treuttel \& Würtz.

Erdtman, G. 1952. Pollen morphology and plant taxonomy Angiosperms. Stockholm, Almqvist \& Wiksell.

Erdtman, G. 1969. Handbook of Palinology, Morphology, Taxonomy, Ecology. New York, Hafner Publishing Co.

Gleason, H.A. 1922. Vernonieae. North American Flora 33: 52-95.

Holmgren, P.K, Holmgren, N.H. \& Bainett, L.G., 1990. Index Herbariorum. New York, New York Botanical Garden.

Keeley, S.C. \& Jones, S. 1977. Taxonomic implications of external pollen morphology to Vernonia (Compositae) West Indies. American Journal Botany 64: 576-584.

Kingham, D.L. 1976. A study of pollen morphology of tropical African and certain other Vernonieae (Compositae). Kew Bulletin 31: 9-26.

Macleish, N.F.F. 1987. Revision of Eremanthus (Compositae: Vernonieae). Annals of the Missouri Botanic Garden 74: 265-290.

Melhem, T.S. \& Matos, M.E.R. 1972. Variabilidade de forma nos grãos de pólen de Eriope crassipes Benth. Labiatae. Hoehnea 2: 1-10.

Punt, W.; Blackmore, S.; Nilsson, S. \& Le Thomas, A. 1999. Glossary of pollen and spore terminology. http:// www.biol.ruu.nl/ palaeo/glossary/glos-int.htm (Acesso em: 18/04/1999).

Robinson, H. 1987a. Studies in the Lepidaploa Complex (Vernonieae: Asteraceae) - I. The Genus Stenocephalum Sch. Bip. Proceedings of the Biological Society of Washington 100: 578-583. 
Robinson, H. 1987b. Studies in the Lepidaploa Complex (Vernonieae: Asteraceae) - II. A New Genus Echinocoryne. Proceedings of the Biological Society of Washington 100: 584-589.

Robinson, H. 1987c. Studies in the Lepidaploa Complex (Vernonieae: Asteraceae) - III. Two New Genera, Cytocymura and Eirmocephala. Proceedings of the Biological Society of Washington 100: 844-855.

Robinson, H. 1988a. Studies in the Lepidaploa Complex (Vernonieae: Asteraceae) - IV. The new Genus Lessingianthus. Proceedings of the Biological Society of Washington 101: 929-951.

Robinson, H. 1988b. Studies in the Lepidaploa Complex (Vernonieae: Asteraceae) - V. The new Genus Chrysolaena. Proceedings of the Biological Society of Washington 101: 952-958.

Robinson, H. 1989. Acilepidopsis, a New Genus of Vernonieae from South America (Asteraceae). Phytologia 67: 289-292.
Robinson, H. 1992a. Mesanthophora, a New Genus of Vernonieae (Asteraceae) from Paraguay. Novon 2: 169-172.

Robinson, H. 1992b. A New Genus Vernonanthura (Vernonieae, Asteraceae). Phytologia 73: 65-76.

Robinson, H. 1999. Generic and Subtribal Classification of American Vernonieae. Smithsonian Contributions to Botany 89: 1-116.

Salgado-Labouriau, M.L. 1973. Contribuição à Palinologia dos Cerrados. Rio de Janeiro, Academia Brasileira de Ciências.

Schultz-Bipontinious, C.H. 1861. Cassiniaceae uniflorae. Jahresbericht der Pollichia 18-19: 157-190.

Schultz-Bipontinious, C.H. 1863. Geschichte der Gattung Lychnophora Martius. Jahresbericht der Pollichia 20-21: 329-439.

Sprengel, C. 1826. Pp. 1-936. In: C. Linnaei. Systema Vegetabilium. Gottingae. v.3, $16^{\text {th }}$ ed.

Stix, E. 1960. Pollenmorphologische Untersuchungen an Compositen. Grana Palynologica 2: 41-114. 